\title{
A METAMORFOSE DAS FORMAS EM TATIANA BLASS
}

\author{
Viviane Baschirotto \\ UDESC/PROMOP
}

RESUMO: Este artigo é uma pequena parte da dissertação de mestrado defendida em 2015 que se ocupou de pensar 0 gesto artístico da artista visual brasileira Tatiana Blass. Cada artista possui um gesto que carrega consigo, que se encontra como uma persistência e recorrência em sua produção e sempre retorna. Um dos gestos da artista se encontra na metamorfose das formas com os usos distintos de meios e materiais. Utilizando principalmente os conceitos de arquidesenho de Yves Alain Bois e acontecimento de Gilles Deleuze, 0 artigo se propõe a refletir sobre a plausibilidade do gesto da metamorfose em suas obras tridimensionais que se encontram entre escultura, performance e instalação.

PALAVRAS-CHAVE: Tatiana Blass. Metamorfose. Formas.

\section{THE METAMORPHOSIS OF FORMS IN TATIANA BLASS}

ABSTRACT: This article is a small part of the dissertation defended in 2015 who engaged in thinking the artistic gesture of the Brazilian visual artist Tatiana Blass. Each artist has a gesture that carries with it, which is as a persistence and recurrence in production and always returns. One of the artist's gesture is the metamorphosis of forms with different uses of media and materials. Mainly using the concepts of arquidesenho Yves Alain Bois and event Gilles Deleuze, the article aims to reflect on the plausibility of Metamorphosis gesture in their three-dimensional works that lie between sculpture, performance and installation.

KEYWORDS: Tatiana Blass. Metamorphosis. Forms.

é doutoranda em Teoria e História da Arte do Programa de Pós-Graduação em Artes Visuais da Universidade do Estado de Santa Catarina. 


\title{
A METAMORFOSE DAS FORMAS EM TATIANA BLASS
}

\author{
Viviane Baschirotto
}

O que poderia ser considerada uma metamorfose dentro da arte? Talvez uma transformação da forma. Mas somente isso? Quem sabe também uma mistura de diferentes materiais? Ou uma nova forma de enxergar um objeto? Ou ainda um acontecimento? Nas obras de Tatiana Blass (1979, nasceu vive e trabalha em São Paulo) a metamorfose das formas se faz presente em diferentes aspectos. Apresenta-se na modificação dos usos dos objetos do cotidiano, como os instrumentos musicais, ou com os diferentes tipos de materiais que a artista utiliza e que acabam por modificar as formas. São diferentes tipos de metamorfoses que as obras da artista sofrem, e quando muda a situação, muda-se também o estado metamórfico. Segundo o dicionário Houaiss", metamorfose é a "mudança completa de forma, natureza ou estrutura; transformação, transmutação" e, na natureza, o dicionário utiliza o exemplo da lagarta que se transforma em borboleta, neste caso, uma mutação da forma física, como acontece em algumas obras da artista.

Uma obra da artista onde também se pode encontrar a transformação das formas é Entrevista 1.3 (Figura 1), da Série Entrevista. Neste trabalho, o que parece ser uma cabeça está presa na parede na altura aproximada de uma cabeça humana, cinco microfones estão presos a ela de uma forma que parece violenta, pois desfiguraram o rosto da personagem. Dos microfones saem seus fios, cabos de ligação, que estão presos na parede abaixo, distribuídos de maneira disforme. O que seria dito é calado pelos microfones pressionados no rosto. $\mathrm{O}$ que remete a um rosto humano, com a adição dos microfones lembra um ser monstruoso, talvez um polvo marinho, mas um polvo cujas garras são feitas de microfones e fios. Seria um polvo impossível. Um monstro metade humano, metade máquina. Na metamorfose entre a cabeça humana e os microfones o que se encontra é uma forma bestial, uma forma composta por duas partes distintas, que ao se fixarem dão vida a uma aparência desconhe-

\footnotetext{
${ }^{1}$ HOUAISS, Antônio et al. Dicionário Houaiss da língua portuguesa. Rio de Janeiro: Objetiva, 2004, p. 1282.
} 
cida. Seria essa forma um odradek, tal como Kafka descreve, um ser sem forma apropriada?

Poderíamos ficar tentados a acreditar que essa estrutura algum dia teve uma forma adequada a determinada função, e que agora está quebrada. No entanto não parece ser o caso; pelo menos não há nenhum indício nesse sentido; não há remendos nem fraturas visíveis; o conjunto parece inutilizável, mas a seu modo completo. Nada mais podemos dizer, porque Odradek é extraordinariamente móvel e não se deixa capturar. ${ }^{2}$

Figura 1 - Tatiana Blass. Entrevista 1.3. 2013.

Ferro fundido e cabos de ferro. Aproximadamente $180 \times 80 \times 50 \mathrm{~cm}$.

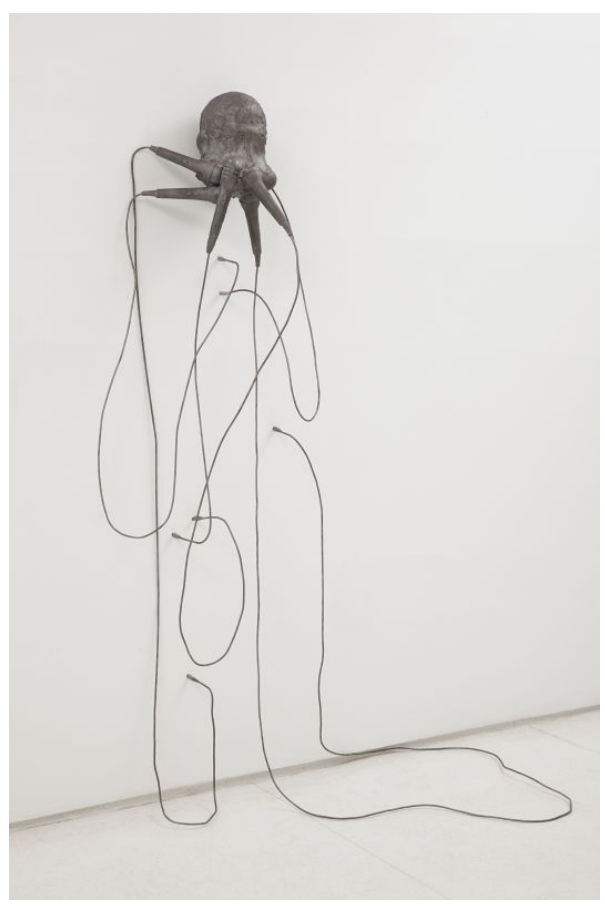

O odradek parece não ter função, pois está quebrado, não se conhece sua forma. Não se sabe para que serve o ser odradek. É um ser que não possui um equivalente, é inclassificável, assim como a obra de arte. Suscita a pergunta: O que é isso? Assim como a obra Entrevista 1.3, que na junção de duas formas conhecidas que são uma cabeça humana e microfones, faz com que o observador se pergunte o que é isso? É um humano? Um polvo? O que é

2 KAFKA, Franz. Odradek. In: BORGES, Jorge Luis. O livro dos seres imaginários. São Paulo: Companhia das Letras, 2007, p. 159-160. 
aquilo, microfones? Por que estão juntos? Para qual finalidade? Na metamorfose que sofre aquele rosto humano desfigurado com a adição violenta dos microfones, o odradek de Tatiana Blass transforma-se em um ser cujo nome não conhecemos, cuja função é ignorada e a forma não pode ser definitivamente nominada e descrita.

Como se essa obra fosse como o texto de Nuno Ramos $O$ velho em questão, onde há um ser que a princípio parece espectral e que pode se transformar em qualquer coisa que toque, embora seu maior desejo seja no fim da vida virar uma pedra. Na metamorfose das formas, a personagem se encontra entre homem e animal, um ser bestial com alma humana. "Vem mais uma noite e entre todos os animais que sou eu sou aquele animal que dorme, nunca lembro do sonho mas sei que durei mais um dia. Toco então o elemento em que me transformo, às vezes porque quero, às vezes não." ${ }^{3}$

Em determinado momento, enquanto é lobo e ataca um velho, a personagem assume a forma do velho em questão e sendo ele, incorpora suas lembranças. Passado algum tempo, se prepara para um dia tocar a pedra que quer ser. Como no ciclo da vida de cada ser humano, que um dia irá virar um pedaço de massa sem vida, silenciosa. As obras de Tatiana Blass também se metamorfoseiam como a personagem de Nuno Ramos, e se transformam em outra coisa, nesse ser que não sabemos nomear.

De transformação também trata o livro Metamorfoses de Ovídio ${ }^{4}$, onde cada poema seu conta uma história onde os personagens de alguma maneira se modificam. O escritor narra suas metamorfoses desde o início do livro quando escreve sobre a criação do mundo: "Portanto, a fértil mãe, a extensa terra. Do recente dilúvio repassada, E pelo aéreo lume escandecida, Inúmeras espécies foi brotando: Deu ser a algumas com a forma antiga. Noutras enfim criou não vistos monstros." ${ }^{5}$ Até o fim de seu livro as metamorfoses aparecem e não seria diferente na narração da história de Cadmo e Hermíone, quando conta que Cadmo sai da cidade que construiu, vaga por um longo tempo e acaba por parar em llíria e lá exclama:

Ah! Sagrada talvez era a serpente. Que no bosque matei quando expelido. De Sidônia me vi por lei paterna! Sacro seria o monstro, em cujos dentes pela terra espalhei semente infensa! Pois se dos numes o furor se apura. Tanto, e tanto em

\footnotetext{
${ }^{3}$ RAMOS, Nuno. O velho em questão. In: O pão do corvo. São Paulo: Editora 34, 2001, p. 22.

${ }^{4}$ Ibidem, p. 56.

${ }^{5}$ OVÍDIO, Públio. Metamorfoses. São Paulo: Martin Claret, 2006, p. 33.
} 
vingá-lo, imploro aos numes. Que em comprida serpente me transformem. ${ }^{6}$

Cadmo demonstra sua vontade em se tornar serpente, seu desejo é atendido e nela ele começa a se transformar. Vê nascer a escama, a cauda e cai de peito na terra. Na metamorfose ainda restam-lhe braços e ainda pode dizer algumas palavras antes que sua língua se fende, pois "Falecem-lhe as palavras" como conta Ovídio. Sua esposa Hermíone o vê nessa situação e se desespera, clama por ser transformada na mesma forma horrenda. Mas Cadmo a lambe a face, e como pode, abraça seu peito. Todos ficam aterrados, mas ainda não com medo, pois Cadmo ainda não tem dentes ferozes e veneno. Ao fim do conto ele se transforma totalmente e de homem passa a ser serpente.

As transformações que sofre Cadmo de homem a serpente perdendo seus membros, acrescentando escamas e o desaparecimento gradativo da fala é similar às transformações sobre o rosto de Entrevista 1.3, pois o ser que a artista constrói também perde sua fala e também não possui seus membros, como se fossem substituídos pelos fios do microfone. Mas em vez de se transformar de homem para animal como acontece com Cadmo, a cabeça que a artista apresenta se funde em uma mistura do homem com o objeto, nesse odradek, nesse ser inclassificável.

\section{AS METAMORFOSES E USOS DA MATÉRIA}

Nas formas metamorfoseadas de Tatiana Blass juntam-se diferentes meios e matérias que se combinam para formar as obras. Em Entrevista 1.3 se fazem presentes na escultura de ferro fundido com a adição de fios de microfone, e até mesmo os microfones de ferro, que lembram os originais. A obra se torna uma instalação a partir do momento em que ocupa o espaço, mas rompe os limites não apenas da escultura, sendo uma instalação, mas a própria obra posta presa na parede remete a uma pintura. Outro exemplo que mistura diferentes linguagens da arte é Metade da fala no chão - piano surdo (Figura 2), obra que faz uma combinação de escultura, performance, instalação e vídeo. A obra consiste em um músico executando cinco músicas de Chopin enquanto simultaneamente baldes de cera líquida são jogadas dentro do piano. Montada duas vezes, a primeira versão, produzida em um teatro, é registrada em vídeo que permanece na exposição da 29a Bienal de São Paulo

\footnotetext{
${ }^{6}$ Ibidem, p. 55.
} 
para onde foi produzida, junto ao segundo piano, onde executada novamente pôde ser acompanhada a performance pelo público. A obra também é uma performance, pressupondo a ação e a cena construída, pois o público pôde acompanhar na abertura da exposição o pianista executando as músicas e a equipe aplicando a cera líquida. Piano Surdo ainda pode ser vista como uma escultura, dada sua tridimensionalidade, mas também uma instalação, pois conversa com o espaço e o utiliza para sua realização, considerando que a cera está também no chão, abaixo do piano.

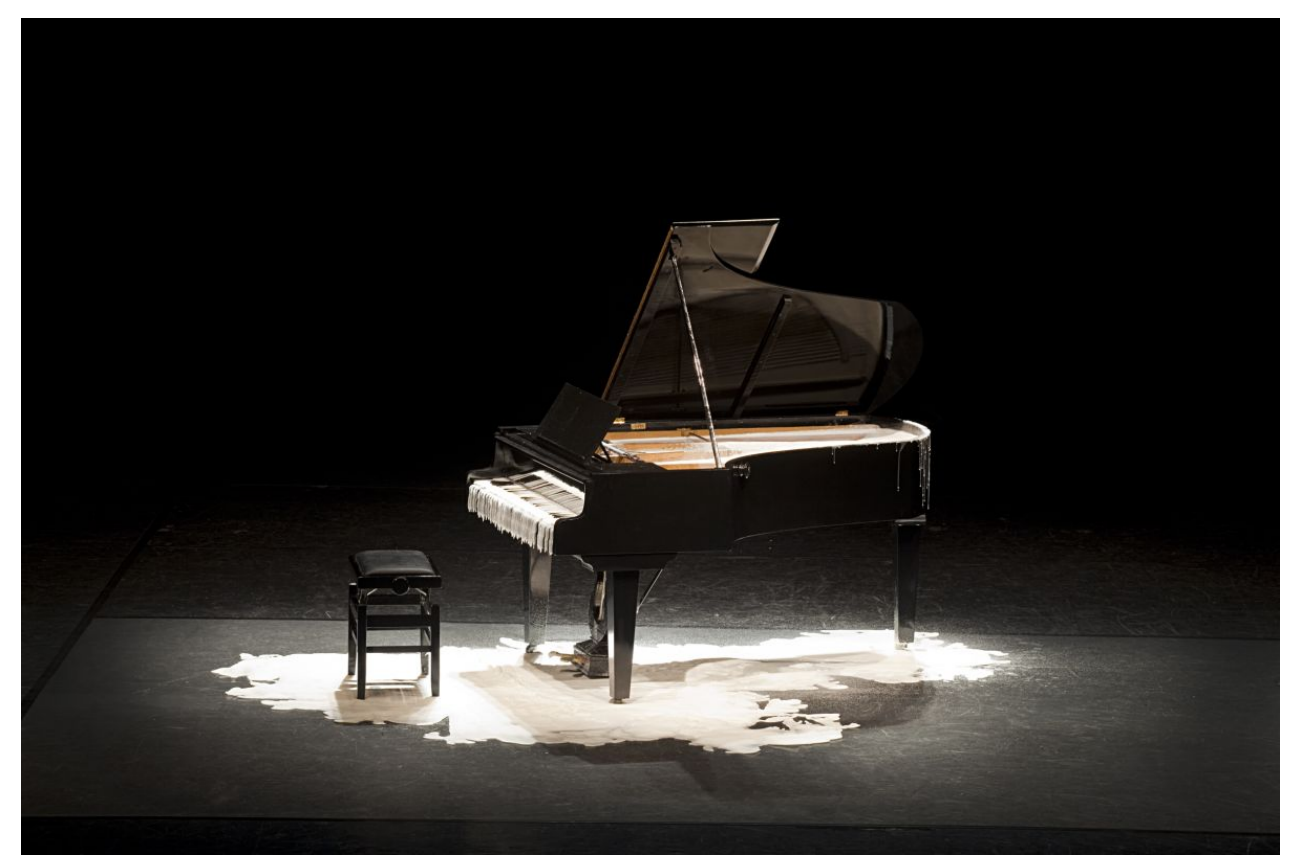

Figura 2 - Tatiana Blass. Metade da fala no chão - piano surdo. 2010.

Piano de cauda, cera microcristalina, vaselina, pianista.

Tatiana Blass designa suas obras em cera como esculturas-performances e abre uma fenda para se pensar a respeito dessa junção de linguagens. $O$ artista brasileiro Tunga (1952), abordou esta junção criando o termo instauração, onde "o conceito visava inicialmente substituir o uso impróprio dos termos 'instalação' e performance."7 $\mathrm{O}$ artista reflete sobre a nomeação e o

${ }^{7}$ LAGNADO, Lisette. A instauração: um conceito entre instalação e performance. In: BASBAUM, Ricardo (Org.). Arte contemporânea brasileira. Texturas, dicções, ficções estratégias. Rio de Janeiro: Rios Ambiciosos, 2001, p. 371. 
discurso, que criam conflitos de interpretações. Lisette Lagnado em seu texto A Instauração: um conceito entre instalação e performance lembra que as expressões "escultura de ação" ou "pintura viva" são expressões recentes que sugerem uma mudança na percepção da estrutura do sujeito-objeto e afirma que:

Para um futuro próximo, o problema colocado pela instauração diz respeito às condições de existência de um artista que expõe os resíduos de uma passagem transitória sobre a matéria. [...] os efeitos da temporalidade sobre a arte nunca assumiram uma expressão tão direta: intensificar a duração apenas enquanto ela está durando. $^{8}$

Essa mistura de diferentes formas de se fazer arte como quando trabalha com suas esculturas/performances ou com instauração, para usar o termo cunhado por Tunga, não foi inventada por Tatiana Blass, ela é consequência da arte moderna, da qual a artista é herdeira. E talvez quem primeiro deu-se conta dessa mistura de técnicas e sua não hierarquização foi o francês Henri Matisse (1869-1954). Pode-se pensar nessa junção de diferentes técnicas feitas por Tatiana Blass como uma herança do que Yve-Alain Bois definiu como arquidesenho em seu texto $A$ pintura como modelo, onde reflete sobre a consciência que Matisse possuía sobre essa não diferenciação. $O$ artista cria uma nova equação para a relação entre desenho e cor. Desenho e pintura andam juntos, não há diferença entre um e outro. Matisse afirma:

\begin{abstract}
Quando uso tinta, tenho uma percepção da quantidade - superfície de cor que é necessária para mim, e modifico seu contorno a fim de determinar claramente, e de maneira definitiva, meus sentimentos (Chamemos a primeira ação de 'pintar', e a segunda de 'desenhar'). No meu caso, pintar e desenhar são uma coisa só. Escolho a quantidade de superfície colorida e faço com que ela se ajuste ao meu sentimento do desenho [...]. ${ }^{9}$
\end{abstract}

No caso da obra The dessert: hamnony in red (Figura 3), Matisse utiliza a cor vermelha em todo o ambiente. A obra é um híbrido entre desenho e pintura, pois não se sabe delimitar exatamente os objetos. A estampa da parede é a mesma da toalha de mesa, e o observador fica sem saber o que é mesa e o que é parede. $\mathrm{O}$ ambiente todo se funde em função do vermelho que toma

\footnotetext{
8 Ibidem, p. 376.

${ }^{9}$ BOIS, Yve-Alain. A pintura como modelo. São Paulo: WMF Martins Fontes, 2009, p. 68.
} 
conta da sala de jantar e abre apenas uma fenda no canto esquerdo quando se avista uma paisagem, onde não está claro se é possível vê-la porque ali se encontra uma janela aberta ou se é um quadro pendurado na parede. Esta obra se encaixa no conceito de arquidesenho, quando desenho e pintura convivem na mesma obra e quando não há hierarquia entre as técnicas.

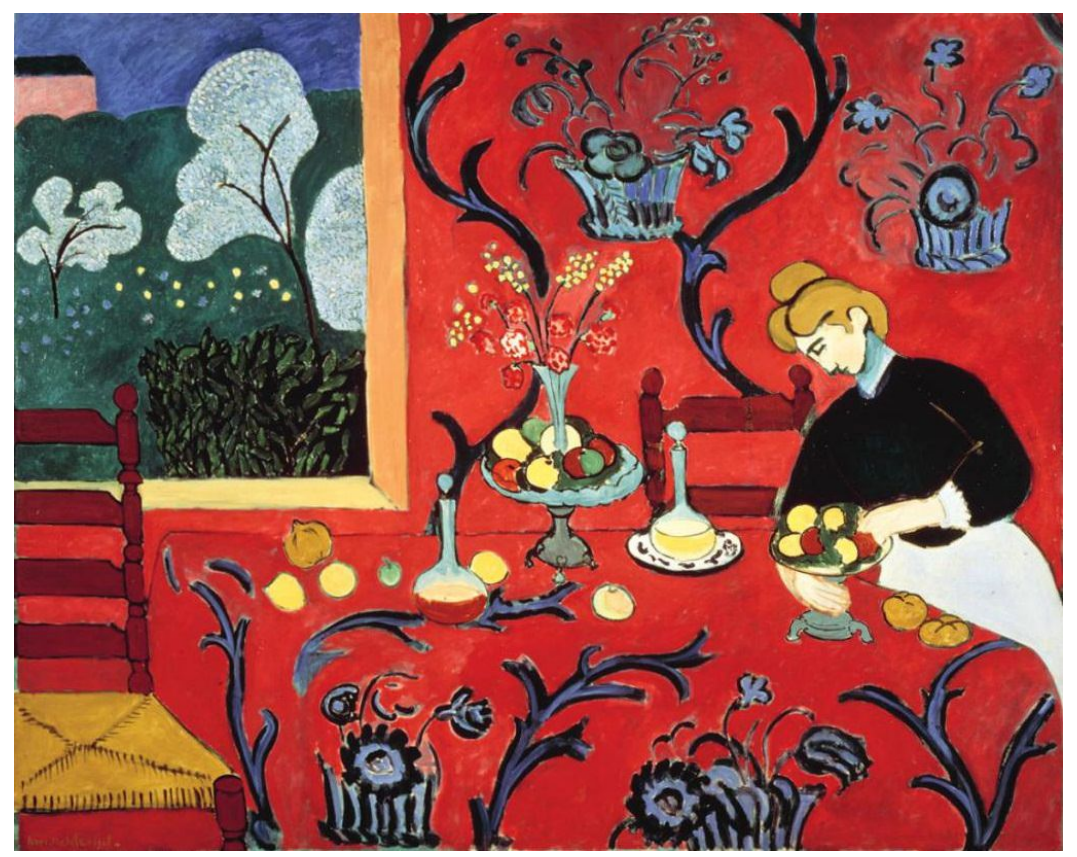

Figura 3 - Henri Matisse. The dessert: harmony in red. 1908. Óleo sobre tela. 180 × $220 \mathrm{~cm}$.

Esse pensamento sobre o arquidesenho que Bois reflete é na verdade inspirado no conceito de arquiescrita cunhado por Jacques Derrida em seu livro Da gramatologia, onde o autor retira toda a ordem e hierarquia do discurso e escrita. Bois então apoiado nesse raciocínio origina o termo arquidesenho para refletir sobre as questões que Matisse levantou na arte, quando ignorou a separação entre a concepção e execução e entre desenho e cor. O desenho e a pintura seriam um espelhamento de uma técnica na outra. A cor não está hierarquizada, o artista consegue fazer essa ruptura entre desenho e cor, onde ambos misturam-se. O artista cria uma nova equação para a relação entre desenho e cor, na quantidade-qualidade. Matisse faz esse salto primeiro 
com suas xilogravuras, com contornos espessos e grandes áreas de branco. Depois preocupa-se em conseguir a mesma qualidade em suas pinturas como em The dessert: the harmony in red.

Bois afirma: "Matisse, para a opinião geral o maior colorista do século, frequentemente considerasse seus desenhos mais bem-sucedidos do que sua pintura: [...] o arquidesenho atua de maneira mais direta no desenho, desnudando a disposição do espaço." 10 O autor ainda afirma que durante muito tempo a cor era apenas o complemento do desenho, quando os artistas começavam por ele e depois acrescentavam a cor. Matisse executa seus desenhos pensando na cor, mesmo a branca do fundo, no espaço que ocupa e cria suas pinturas também com o desenho, com contornos espessos. A própria pintura em Matisse é um contorno. Mas o artista, segundo o autor, não acreditava que existia uma hierarquia a ser resolvida, para ele, ela nunca existiu.

\footnotetext{
[...] quando se tornou impossível distinguir entre o limite e a divisão que ele forma na superfície, impossível contrapor um contorno do que ele contém, quando o desenho passou a 'dominar', a ponto de o próprio espaço tornar-se o principal determinante das relações de cor - foi então que Matisse pôde começar a enaltecer a cor. ${ }^{11}$
}

O arquidesenho então é a não-hierarquia entre desenho e cor, uma questão da qual muitos artistas que vieram depois de Matisse internalizaram em seus trabalhos. Tatiana Blass é mais uma herdeira desse pensamento da mistura das técnicas, de tratá-las não mais como uma melhor que a outra, mas trabalhar em conjunto, com diferentes meios e materiais para que a obra seja executada da melhor forma possível. A metamorfose então pode ser uma questão matérica, onde uma técnica imbrincada na outra se transforma em outra coisa, em um arquidesenho na junção do desenho e da pintura ou em uma instauração na combinação de instalação e performance. Matisse enalteceu desenho e cor, para andarem lado a lado, e por mais inconscientes que os artistas contemporâneos sejam a respeito do que o artista levantou na arte, hoje há uma recorrência na mistura dos materiais, uma junção de linguagens, metamorfoses e hibridação de técnicas, que também se faz presente nas obras de Tatiana Blass.

\footnotetext{
10 Ibidem, p. 76.

11 Ibidem, p. 80 .
} 


\section{METAMORFOSE COMO UM ACONTECIMENTO}

Assim como Piano Surdo (Figura 2), outras obras fazem parte da série Metade da fala no chão de Tatiana Blass que conta em sua maioria com instrumentos musicais que são calados, desde o piano até uma bateria ou uma tuba. Alguns instrumentos são calados com a cera, outros com tubos de latão e ainda com bronze fundido como é o caso da obra Clarinete (Figura 4).

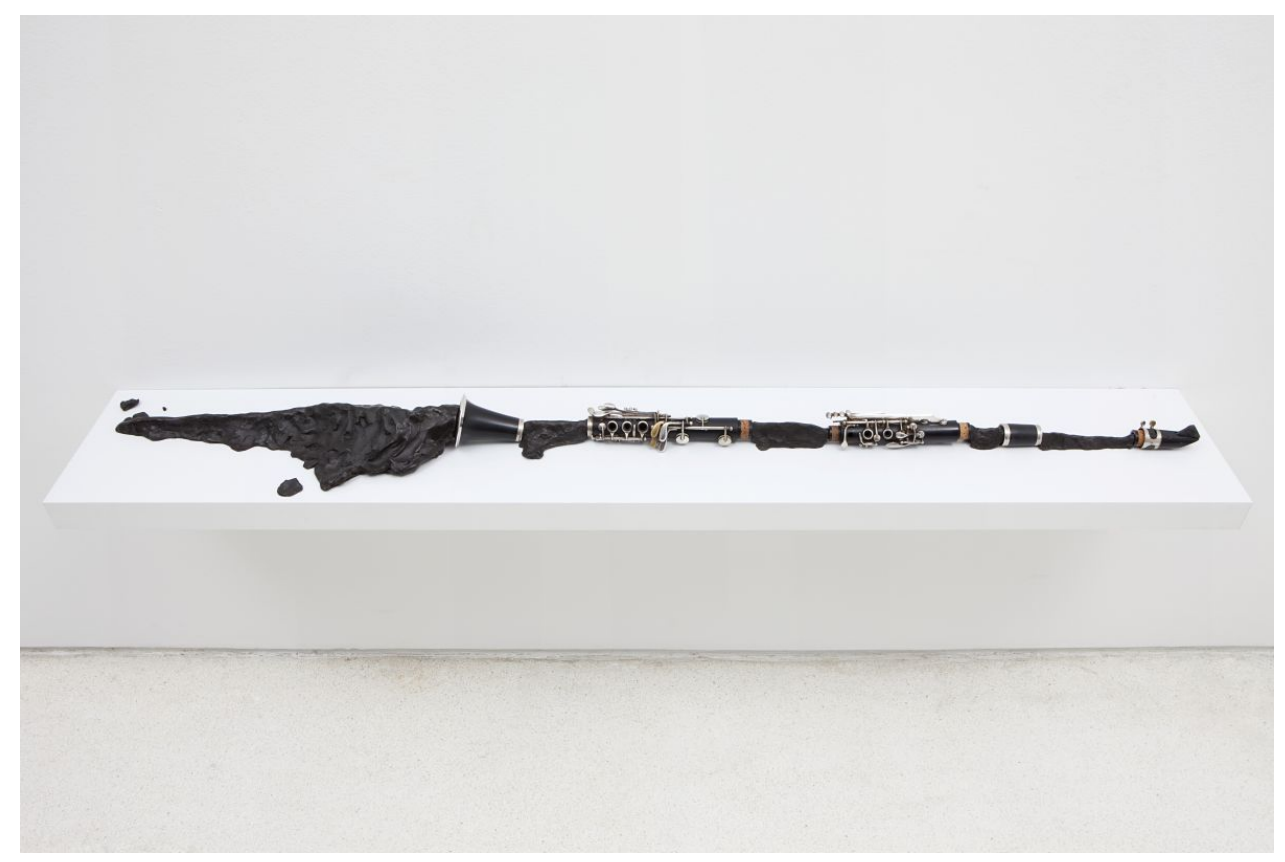

Figura 4 - Tatiana Blass. Metade da fala no chão - Clarinete. 2012.

Clarinete e bronze fundido. $10 \times 180 \times 30 \mathrm{~cm}$.

Nesta obra um clarinete é inutilizado como um instrumento musical por meio de sua junção com o ferro fundido, que parece perpassar por entre o tubo do instrumento e vazar em algumas partes ao longo de sua extensão para desembocar na abertura de onde o som deveria sair, agora ocupado com um material escuro endurecido após um aparente processo de derretimento. $\mathrm{O}$ instrumento parece ter sido dissolvido em algumas partes, como se fosse mais uma de suas obras em cera, mas dessa vez ao contrário do derretimento acontecendo, vemos um resultado final de um derretimento falso na junção do ferro fundido com o clarinete. O instrumento que se transformou, deu 
lugar a um novo formato, a uma forma que carrega a junção de dois materiais diferentes, um instrumento musical e um material em uma forma bruta, o ferro fundido, mas que com a sugestão de um derretimento que teria acontecido, torna-se uma forma orgânica que perpassa o objeto.

Figura 5 - Tatiana Blass. Cauda Cadeira. 2005. Cadeira de madeira e madeira laqueada. $100 \times 150 \times 200 \mathrm{~cm}$.

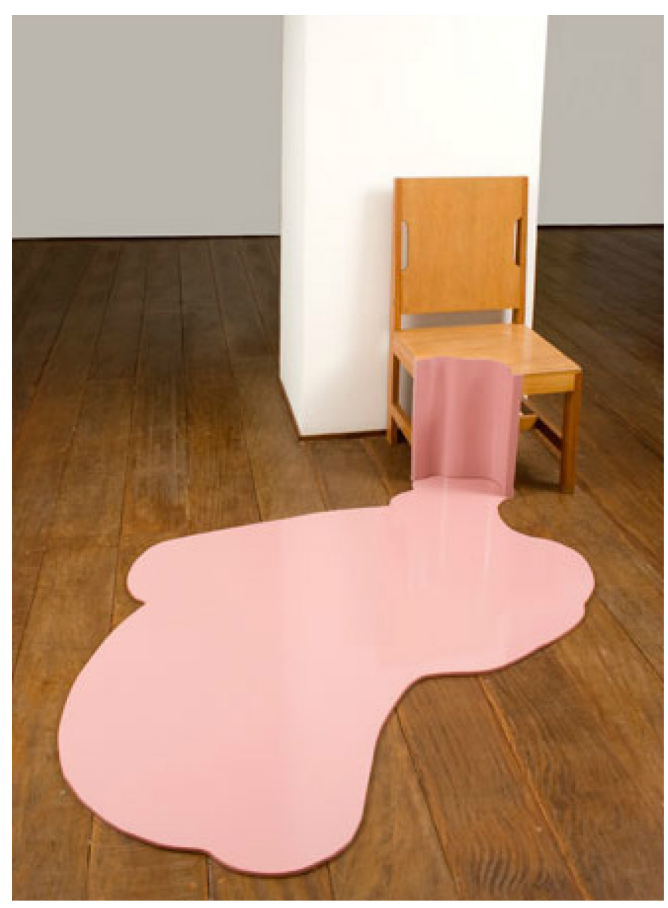

O gesto de metamorfosear os objetos não é uma característica que se encontra apenas nas obras mais recentes da artista. No início de sua produção artística, Tatiana Blass trabalhou com um derretimento simulado em Cauda Cadeira (Figura 5). Nesta obra uma cadeira aparece em uma sala expositiva com uma parte de seu assento faltando, como se tivesse sido abocanhado e, como uma extensão de si, um aparente escorrido cor de rosa claro vai do assento até o chão. Em Cauda Cadeira, assim como em Clarinete, o derretimento e dissolução do material se faz presente pois ambas possuem um escorrido que não é maleável, que se faz de uma ilusão. Como se a cadeira feita de madeira pudesse estar derretendo, sendo feita de um material flexível e, além disso, sua cor rosa laqueada desse um tom onírico à obra, como se ela tivesse saído de um conto de Lewis Carroll, o escritor de Alice no país das maravilhas. Os objetos derretidos ou que sugerem um derretimento fazem 
parte das ficções imaginadas pela artista e traem os olhos do observador com as ilusões de sua dissolução.

Seriam essas ilusões acontecimentos? Talvez as conjunções de materiais que tanto fazem parte das obras da artista. No livro A dobra: Leibniz e o barroco Gilles Deleuze reflete sobre o que é um acontecimento em um de seus capítulos e afirma que "o acontecimento produz-se em um caos, em uma multiplicidade caótica." 12 Seriam os derretimentos de Tatiana Blass fruto de um caos então? Deleuze trata do caos como uma abstração e se pergunta como o caos se torna alguma coisa, que seria quando algo acontece. E aponta algumas condições para o acontecimento, uma delas seria a extensão. "Há extensão quando um elemento estende-se sobre os seguintes, de tal maneira que ele é um todo, e os seguintes, suas partes." ${ }^{13}$ Talvez os objetos metamorfoseados da artista possam ser vistos como extensões, onde um material se funde com outro e se torna ele mesmo, onde o ferro fundido encontra o clarinete, ou onde a cadeira estende-se por si mesma em seu derretimento impossível. "As extensões não param de se deslocar, ganhando e perdendo partes levadas pelo movimento." ${ }^{14}$ Estão em constante movimento.

O acontecimento seria ainda como o gesto de produzir uma vibração em tal potência, como uma onda sonora, como um material que se dilui e se transforma em outro, como uma extensão, como os materiais de Clarinete e Cauda Cadeira, que diluem e se transformam, deixam de ser um instrumento musical e uma cadeira e passam a ser um outro objeto, uma escultura. A vibração produz novos encontros e aproximações com diferentes materiais ou pensamentos. Deleuze ainda aponta outra condição para o acontecimento que seria as séries extensivas vistas como intenções e intensidades, como na transformação dos materiais nas obras de cera da artista, que se modificam por meio da intenção da luz acesa e dependem de sua intensidade para acontecerem, como um desígnio. E mais um componente do acontecimento seria o indivíduo, fundamental na apreensão dos elementos: "Se denominamos elemento o que tem partes e é uma parte mas também o que tem propriedades intrínsecas, dizemos que o indivíduo é uma 'concrescência' de elementos" $^{15}$. O indivíduo faria parte então de uma quase anomalia, de uma afluência

\footnotetext{
12 DELEUZE, Gilles. A dobra. Leibniz e o barroco. 6. ed. Campinas: Papirus, 1991, p. 134.

13 Ibidem, p. 135.

14 Ibidem, p. 139.

15 Ibidem, p. 136.
} 
entre a obra e o indivíduo.

Em clave semelhante, o acontecimento faz a junção de componentes díspares. Cherem ${ }^{16}$ escreve:

Daí decorre o entendimento de que a arte se constitui como território que abriga tudo aquilo que é tecido pelo pensamento, aceitando as combinações paradoxais de probabilidades e possibilidades, através das quais tanto comparecem as noções operatórias situadas no domínio do plausível, da exatidão e precisão documental, como os procedimentos para onde conflui a escala ficcional.

Essa lógica de combinações de partes distintas e em movimento acontece em Vaga (Figura 6) onde um carro é atolado ao concreto da rampa de estacionamento em frente à Galeria Millan em São Paulo. Vaga fez parte da exposição individual da artista em 2012 na galeria que a representa. Intitulada Acidente, a exposição ainda contava com pinturas e esculturas da artista no interior da galeria. Em Vaga, o carro atolado na rampa parece ter subido no concreto ainda mole, como se o carro tivesse sido submergido em parte deste concreto. Mas assim como o escorrido de ferro fundido de Clarinete e a madeira de Cauda Cadeira, o concreto de Vaga permanece rígido e com uma limpeza a sua volta, em uma fundição da calçada com o carro impecável, onde não se nota seus resquícios.

Nesta obra a artista tira um automóvel de circulação, em um estado de paralização no concreto. A obra suscita diferentes questões, algumas como a relação da duração, a permanência da obra, que durou o tempo em que a exposição aconteceu, outras com relação ao que pode significar um carro atolado em uma cidade como São Paulo, onde o trânsito carregado faz parte da vida de seus moradores, ou ainda sobre um tempo paralisado, sobre um objeto neutralizado, como o carro, que não cumpre mais sua função, assim como todos os objetos que foram desfuncionalizados pela artista, como os nesta seção abordados, o clarinete e uma cadeira. Os objetos são encontrados em uma situação incomum a seu uso e são produzidos intencionalmente como extensões um do outro na junção de suas matérias.

${ }^{16}$ CHEREM, Rosângela Miranda. Três perguntas sobre a persistência das formas e a extravagância das imagens. In: MAKOWIECKY, Sandra; CHEREM, Rosângela Miranda. (Orgs.). Fragmentos - Construção I. Academicismo e Modernismo em Santa Catarina. Florianópolis: Ed. Udesc, 2010, p. 126. 


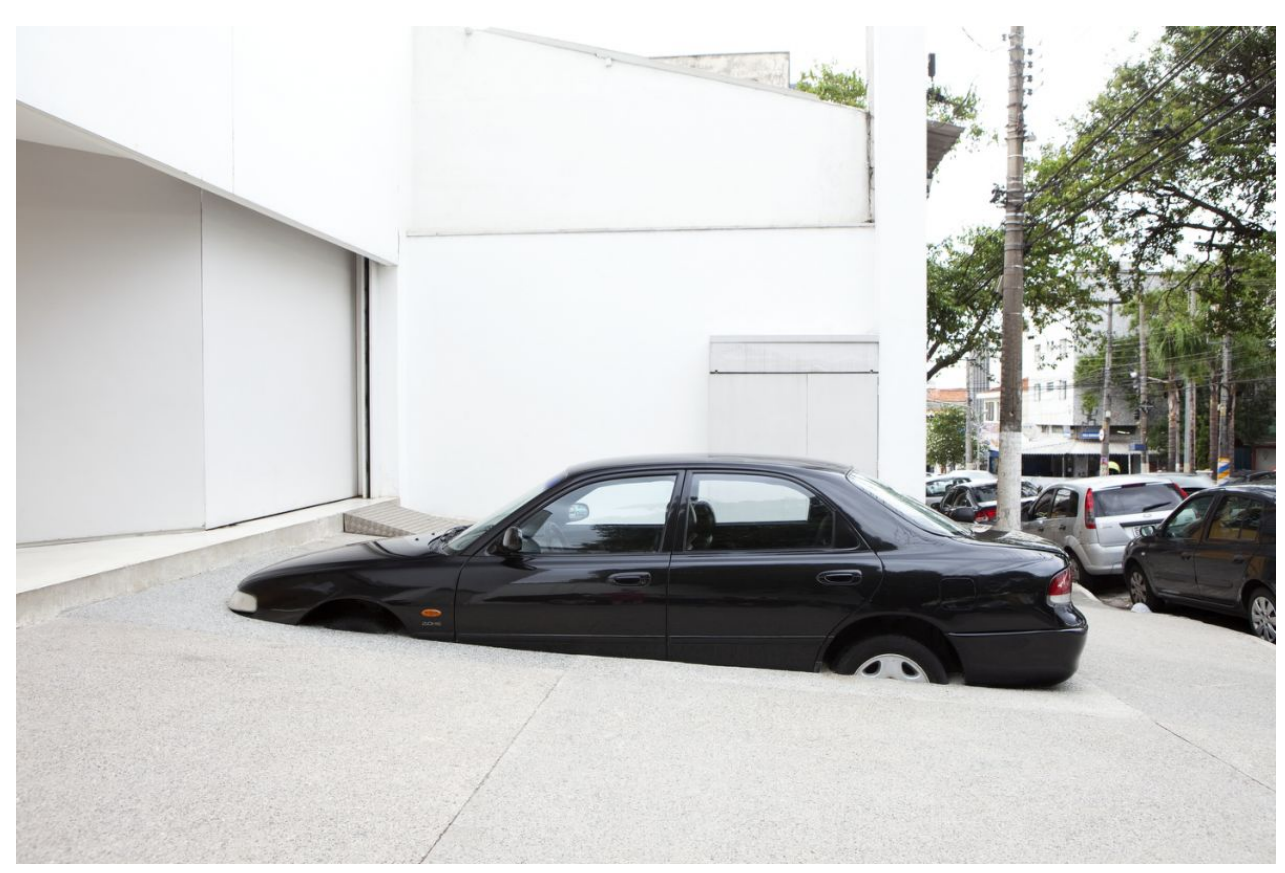

Figura 6 - Tatiana Blass. Vaga. 2012.

Carro Mazda e Fulget. $150 \times 300 \times 500 \mathrm{~cm}$.

Outro componente do acontecimento de Deleuze seriam ainda os objetos eternos como possibilidades que se realizam nos fluxos, como questões que se repetem, como o derretimento e dissolução das coisas em Tatiana Blass. Seria o acontecimento como fluxo, um mesmo rio, mesma coisa e ocasião. Como um fluxo da poética da artista, de seu gesto, que retorna. Ainda para Deleuze o acontecimento é "ao mesmo tempo público e privado, potencial e atual, entra no devir de outro acontecimento e é sujeito do seu próprio devir." ${ }^{17} \mathrm{O}$ acontecimento presente denota o futuro, como em Vaga, onde a obra poderia ser o momento de uma paralização de um acontecimento, pois o carro poderia estar submergindo ainda mais do que está no tempo presente.

O acontecimento se produz em um campo de problemas, agrega elementos díspares mas os tornam coisas plausíveis, seria um modo de articular, de produzir sentido. "Há concerto esta noite. É o acontecimento. Vibrações sonoras estendem-se, movimentos periódicos percorrem o extenso com seus

${ }^{17}$ DELEUZE, Gilles. A dobra, op. cit., p. 137. 
harmônicos ou submúltiplos." ${ }^{18}$ Um concerto é um acontecimento pois em seu arranjo encontram-se diferentes instrumentos que juntos formam o todo. Seria também o calar do som da série Metade da fala no chão um acontecimento? A ausência do timbre, da intensidade do som, poderiam ser também acontecimento? Na junção das formas metamorfoseadas das obras com materiais improváveis que se encontram como um piano e a cera líquida, o clarinete e o ferro fundido, a cadeira e seu escorrido laqueado e o carro e o concreto, o acontecimento se encontra em sua junção, na formação de inflexões, de linhas curvas e orgânicas e formam as obras de arte.

Tatiana Blass se apossa de objetos de uso banal e agrega outros materiais que são, por vezes, muito distintos uns dos outros como em Vaga onde o carro é, de certa forma, também preenchido até certo momento pelo concreto. A dualidade da matéria agrega sentidos e torna o acontecimento um campo de problemas, onde a junção de diferentes materiais se torna plausível nas ficções da artista. As obras são feitas a partir da criação de objetos incomuns à obra de arte tradicional, evidente que não é a única e nem a primeira. Mas com esse gesto da metamorfose das formas a artista é produtora de acontecimentos, de vibrações e intenções transformadas em obras de arte.

${ }^{18}$ Ibidem, p. 141. 